\title{
Modelling post-fire vegetation recovery in Portugal
}

\author{
A. Bastos ${ }^{1}$, C. M. Gouveia ${ }^{1,2}$, C. C. DaCamara ${ }^{1}$, and R. M. Trigo ${ }^{1,3}$ \\ ${ }^{1}$ Instituto Dom Luiz, Universidade de Lisboa, Portugal \\ ${ }^{2}$ Escola Superior de Tecnologia, Instituto Politécnico de Setúbal, Setúbal, Portugal \\ ${ }^{3}$ Dept. Engenharias, Universidade Lusofona, Lisboa, Portugal
}

Received: 26 April 2011 - Published in Biogeosciences Discuss.: 9 May 2011

Revised: 10 November 2011 - Accepted: 25 November 2011 - Published: 12 December 2011

\begin{abstract}
Wildfires in Mediterranean Europe have been increasing in number and extension over the last decades and constitute one of the major disturbances of these ecosystems. Portugal is the country with more burnt area in the last decade and the years of 2003 and 2005 were particularly devastating, the total burned areas of 425000 and 338000 ha being several times higher than the corresponding average. The year of 2005 further coincided with one of the most severe droughts since early 20th century. Due to different responses of vegetation to diverse fire regimes and to the complexity of landscape structures, fires have complex effects on vegetation recovery. Remote sensing has revealed to be a powerful tool in studying vegetation dynamics and in monitoring post-fire vegetation recovery, which is crucial to landmanagement and to prevent erosion.

The main goals of the present work are (i) to assess the accuracy of a vegetation recovery model previously developed by the authors; (ii) to assess the model's performance, namely its sensitivity to initial conditions, to the temporal length of the input dataset and to missing data; (iii) to study vegetation recovery over two selected areas that were affected by two large wildfire events in the fire seasons of 2003 and 2005 , respectively.

The study relies on monthly values of NDVI over 11 years (1998-2009), at $1 \mathrm{~km} \times 1 \mathrm{~km}$ spatial resolution, as obtained by the VEGETATION instrument. According to results from sensitivity analysis, the model is robust and able to provide good estimations of recovery times of vegetation when the regeneration process is regular, even when missing data is present. In respect to the two selected burnt scars, results indicate that fire damage is a determinant factor
\end{abstract}

Correspondence to: A. Bastos (afbastos@fc.ul.pt) of regeneration, as less damaged vegetation recovers more rapidly, which is mainly justified by the high coverage of $P i$ nus pinaster over the area, and by the fact that coniferous forests tend to recover slower than transitional woodlandshrub, which tend to dominate the areas following the fire event.

\section{Introduction}

A marked increase in the number and extent of wildfires has been registered in Mediterranean Europe in recent decades (Röder et al., 2008). Such increase may be either due to landuse changes (e.g. land abandonment and agriculture mechanization) or to climatic warming. Whereas land-use changes lead to fuel accumulation and landscape homogenization, climatic warming induces an increase in fire risk (Pausas and Vallejo, 1999). Within the European Mediterranean context, Portugal is the country with more burnt area in the last decade (JRC-EC, 2009). The years of 2003 and 2005 were particularly devastating with the summer (and annual) total burned areas several times higher than the corresponding average. The outstanding fire season of 2003 registered the maximal burnt area since 1980, with more than 425000 ha burned (DGRF, 2008), representing about $5 \%$ of the Portuguese mainland (Trigo et al., 2006); 2005 registered the second maximal value of burnt area, with about 338000 ha burnt (DGRF, 2008). The exceptional fire season registered in 2005 was coincident with one of the most severe droughts since early 20th century which lasted for more than 9 months in more than one third of the country (Garcia-Herrera et al., 2007; Gouveia et al., 2009). This severe drought had a strong negative impact in vegetation dynamics, since it was contemporaneous with the period of high photosynthetic activity (Gouveia et al., 2009), and may explain the increased tree

Published by Copernicus Publications on behalf of the European Geosciences Union. 
mortality during 2005 and 2006 (Catry et al., 2010). According to Nunes et al. (2005), very large fires in Portugal tend to occur selectively in Pinus pinaster forests, followed by eucalyptus or pine/eucalyptus mixed forests. In fact, $P i$ nus pinaster seems to be facing a drastic reduction in many areas, since fire recurrence intervals usually do not allow regenerating pines to reach reproductive maturity (Fernandes and Rigolot, 2007).

The observed increase in wildfires has a drastic impact on biological productivity and composition of Mediterranean ecosystems (Calvo et al., 2003, 2005). However the effects of fire on ecosystems are very complex since they depend on fire regimes and characteristics (Naveh, 1995) as well as on the response of vegetation to such regimes and on environmental factors (De Luís et al. 2001, 2004). The most important impacts consist on (i) soil impoverishment through loss of nutrients during the fire event or throughout the post-fire period, by runoff; (ii) loss of plant cover and consequent erosion; and (iii) changes in hydro-ecological processes (Moreno and Oechel, 1995; Inbar et al., 1998). Thornes (1990) suggested that a minimum of $30 \%$ in vegetation cover is required to protect the soil against water erosion. If, in the long term, vegetation recovery decreases post-fire runoff and erosion, in the short term, autumn rainstorms increase erosion after summer fires in soils with reduced plant cover (De Luís et al., 2001). Most of the sediment loss seems to occur in the first year after the fire (DeBano et al., 1998; Cerdà and Doerr, 2005) and the longer the time required for vegetation to reach the $30 \%$ minimum threshold, the higher is the erosion risk (Shakesby et al., 1993; Cerdà, 1998; Inbar et al., 1998).

A thorough evaluation of post-fire vegetation recovery is, therefore, crucial in land management (Wittenberg et al. 2007). However the process of vegetation recovery following wildfires is difficult to analyse since it depends on a large variety of biological and environmental factors and on the interaction between them. Many Mediterranean vegetation species are adapted to wildfires through diverse post-fire recovery strategies, such as resprouters, which are able to regenerate rapidly from fire resistant structures (López-Soria and Castell, 1992; Hodgkinson, 1998), and obligate seeders, that recover through germination of fire-resistant seeds stored in the canopy or in the ground (Lloret, 1998; Arianoutsou and Ne'eman, 2000). However, not all Mediterranean species are able to recover after wildfires (Retana et al., 2002) and there is also the problem of the loss of growth capacity of resprouters after recurrent fires (Ferran et al., 1998) and of pine species after highly damaging fires (Pérula et al., 2003). Strong or frequent droughts increase water stress during regeneration, and more concentrated rainfall intensity may intensify erosion and nutrient loss (De Luís et al., 2003), affecting short-term ecosystem development. Furthermore, De Luís et al. (2001) have observed that, in Eastern Spain, changes in the precipitation regime, such as decreases in rainfall volume and increases in rainfall concentration seem to be occurring in dry, inland areas, where most forests are located. Remote sensing has revealed to be a powerful tool to study the climatic influence on vegetation dynamics (Vicente-Serrano and Heredia-Laclaustra, 2004; Julien et al., 2006; Karnieli et al., 2006) as well as to monitor post-fire vegetation recovery over a variety of regions (Epting and Verbyla, 2005; Goetz et al., 2006) that include Mediterranean ecosystems (Wittenberg et al. 2007; Röder et al., 2008; Minchella et al., 2009). Approaches based on remote sensing have also been successfully used to assess fire risk (Chuvieco et al., 2010), burn severity (Epting and Verbyla, 2005; De Santis and Chuvieco, 2007; Kokaly et al., 2007; Miller and Thode, 2007; Fox et al., 2008; Miller et al., 2009) and erosion risk (Fox et al., 2008).

In the above-mentioned context of remote sensing, the Normalized Difference Vegetation Index (NDVI) has proven to be particularly adequate to assess post-fire recovery of Mediterranean ecosystems (Díaz-Delgado et al., 1998; DíasDelgado and Pons, 2001; Hope et al., 2007; Fox et al., 2008; Gouveia et al., 2010) as well as to monitor vegetation dynamics subject to stress conditions such as those associated to major drought events (Gouveia et al., 2009). Several authors (Epting and Verbyla, 2005; Kokaly et al., 2007; Miller and Thode, 2007; Miller et al., 2009) have successfully evaluated burn severity based on temporal changes between preand post-fire satellite imagery, namely by using differences of pre- and post-fire NDVI values (De Santis and Chuvieco, 2007; Fox et al., 2008). When using differencing methods based on an absolute measure of NDVI, low levels of predisturbance chlorophyll may, however, introduce some confusion in the measurement of absolute change, raising the need for relative measures such as the one proposed by Miller and Thode (2007).

Gouveia et al. (2010) have studied post-fire vegetation dynamics in Portugal based on maps of recovery rates as estimated by fitting a mono-parametric model of vegetation recovery to time series of NDVI from the SPOTVEGETATION instrument. However the study has focused on just two large burned areas during the 2003 period. On the other hand the authors have relied on a rather short 8 year time series covering the period 1998-2006 and therefore encompassing only three years after the fire events. Both the reduced number of studied burned areas and the small length of the time series used may undermine the applicability of the model to other regions or fire seasons, thus requiring a more comprehensive analysis. In this context, the main goals of this work are therefore the following:

1. To evaluate the accuracy of the vegetation recovery model developed in Gouveia et al. (2010) using an extended NDVI dataset now available for the 11-year period (1998-2009) and by applying the vegetation recovery model to 7 additional large fire scars resulting from fire events occurring in the fire seasons between 2003 and 2005; 
2. To evaluate the model's performance, focusing on the analysis of sensitivity to initial conditions, to the temporal length of the input data, as well as to missing data;

3. To perform a spatial analysis of the recovery times focusing on two large burnt scars selected from 2003 and 2005 fire seasons and then assess the dependency of recovery rates on fire damage and land-cover types with the aim of identifying relevant driving factors of the regeneration process.

\section{Data}

In the present work, vegetation dynamics is assessed using NDVI datasets as derived from information acquired by the VEGETATION sensor on board of SPOT4 and SPOT5 satellites. VEGETATION is an optical multispectral instrument which has been providing, since 1998, high quality global monitoring on a daily basis of land-cover dynamics, in four spectral bands at $1 \mathrm{~km}^{2}$ resolution (Hagolle et al., 2005). NDVI data were extracted from the so-called S10 products of VITO database (http://free.vgt.vito.be) which consist of time series of 10-day synthesis of the daily products as obtained by the Maximum Value Composite method (MVC), i.e. by simply selecting the highest value of NDVI for each 10-day period for each pixel, a procedure that allows removing most of the cloudy pixels (Holben, 1986). S10 MVC-NDVI values are supplied on a regular latitude-longitude grid, using the WSG84 ellipsoid, at the resolution of $0.008928^{\circ}$. The data considered in the present work were selected for the period spanning from September 1998 to August 2009 over a region extending from $37^{\circ}$ to $42^{\circ} \mathrm{N}$ and from $10^{\circ}$ to $6^{\circ} \mathrm{W}$.

It may be noted that, when supplied, MVC-NDVI data are already calibrated geometrically and corrected for atmospheric and radiometric effects, the latter by means of a linear model that normalizes the Charge-Coupled Device Response, according to the methods described in Maisongrande et al. (2004). Moreover, following Gouveia et al. (2009, 2010), and in order to create a consistent dataset of vegetation dynamics, each annual time-series of MVC-NDVI was analysed and corrected according to the procedure proposed by Stökli and Vidale (2004). The approach involves two steps in the spatiotemporal interpolation process; (i) a replacement of no-data values in the dataset by spatial interpolation and (ii) an adjustment of the NDVI time-series by using a temporal interpolation procedure.

The assessment of land-cover was based on both the Corine Land Cover 2000 (CLC 2000) and the Corine Land Cover 2006 (CLC 2006) maps for Continental Portugal at $250 \mathrm{~m}$ resolution, respectively developed by Instituto Superior de Estatística e Gestão da Informação and the European Environment Agency. Both maps were resampled to the coarser resolution of $1 \mathrm{~km}$ according to the commonly used majority rule (Turner et al., 1989). Land-cover information includes 44 classes, as defined in level 3 which is intended to be used at small scales such as the one used in this work $(1 \mathrm{~km})$.

\section{Methodology}

Detection of large fire scars and analysis of vegetation recovery is based on the approach previously developed in Gouveia et al. (2010). Several improvements to the approach will be proposed in the present work with the aim of guarantying its application to other areas and extended time series. The four main methodological steps consist of (i) identification of burnt areas based on unsupervised clustering of the spatial distribution of monthly values of MVC-NDVI over Portugal; (ii) evaluation of the model's performance, namely the analysis of sensitivity to initial conditions, to the temporal length of the input data, as well as to missing data; (iii) estimation of vegetation recovery rates based on the mono-parametric model of post-fire vegetation recovery; and (iv) analysis of spatial distributions of obtained post-fire vegetation recovery times and of their relationships with pre-fire vegetation density and fire damage.

\subsection{Identification of burnt areas}

Identification of burnt scars in the 2003, 2004 and 2005 fire seasons was performed by means of unsupervised clustering, based on K-means method, (MacQueen, 1967; Hartigan and Wong, 1979), which was applied on a pixel by pixel basis to MVC-NDVI anomalies along the vegetative cycle following each fire season. It is worth noting that anomalies in each pixel were defined as departures from the median values (instead of the less robust mean) during the considered period, in order to minimize the leverage effect of extremely low NDVI values registered in drought years.

In the case of 2003, the procedure was the same as the one described in Gouveia et al. (2010). Two clusters were accordingly obtained by applying K-means to monthly NDVI anomalies from September 2003 to August 2004. Burnt pixels appeared as associated to the cluster whose centroid presented persistent negative anomalies throughout the entire analysed vegetation cycle. In the case of 2004, the K-means cluster analysis performed on monthly NDVI anomalies from September 2004 to August 2005 led to the identification of four clusters. Large burnt scars during 2004 appeared associated to the cluster whose centroid presented persistent negative values of NDVI anomaly during the following vegetative cycle whereas the other three centroids correspond to nonburnt areas. Two of the remaining clusters presented centroids characterized by very low values of NDVI anomalies especially from January until June and contained non-burnt pixels that were moderately or severely affected by the 2005 drought. Finally, in the case of 2005, the cluster analysis of monthly NDVI anomalies from September 2005 to August 2006 allowed the identification of four clusters. As in 

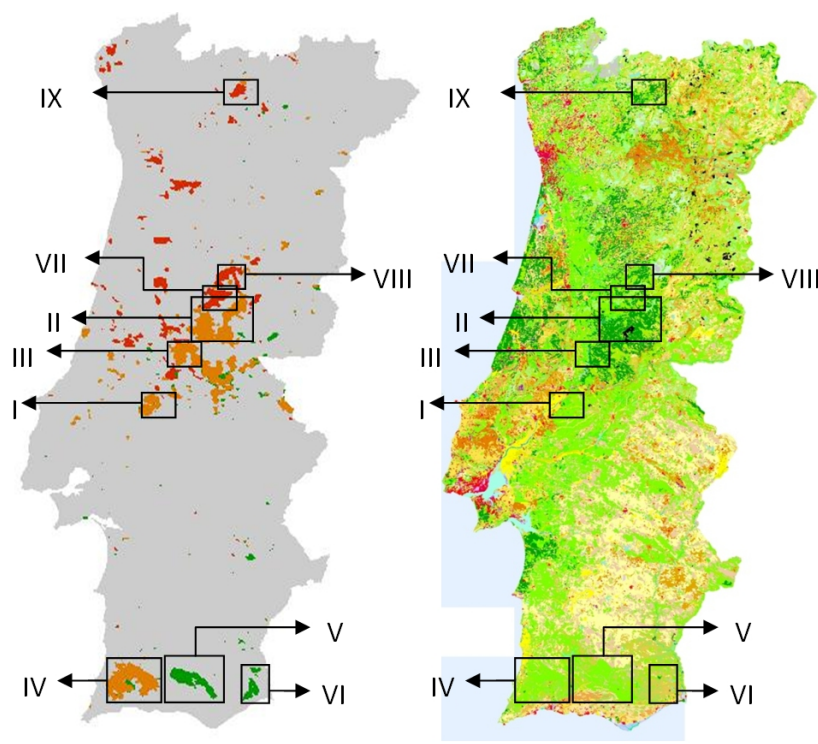

Fig. 1. Burnt areas in Continental Portugal in 2003 (orange pixels), 2004 (green pixels) and 2005 (red pixels) as obtained by cluster analysis of NDVI anomalies over the year following each fire season (left panel). Corine Land-cover 2000 map for Continental Portugal at $1 \mathrm{~km}$ spatial resolution (right panel). Selected areas for the present work and respective nomenclature are identified by the rectangular frames labelled from I to IX.

the case of 2004, the centroid corresponding to the cluster of burnt areas was characterized by systematically low negative values of monthly anomalies, whereas the other three corresponded to non-burnt areas. Two of the latter clusters presented centroids with negative anomaly values, especially in the last months of 2005 and were identified as grouping pixels associated either to scars recovering from fires in previous years or to non-burnt areas affected by the 2004/05 drought which lasted for more than 9 months and affected more than one third of the country (Gouveia et al., 2009).

It is worth stressing that when analysing the years of 2004 and 2005, contamination from previous fire episodes was taken into account. In fact, some pixels kept very low values of NDVI anomaly for more than one year after the fire, especially in the case of pixels corresponding to burnt scars from the devastating 2003 fire season, as identified in Gouveia et al. (2010), whose recovery was markedly affected by drought. These pixels were therefore removed from the subsequent cluster analyses. Results obtained (Fig. 1, left panel) were compared to official maps of burnt areas provided by Portuguese National Forest Authority (ANF) which are based on end-of-fire-season Landsat (2000-2004) and MODIS (2005) imagery (not shown). A set of 9 large burnt areas (labelled from I to IX) was finally selected covering different geographical locations in Continental Portugal and corresponding to a variety of land-cover types (Fig. 1, right panel).

\subsection{Model of vegetation recovery}

Estimation of vegetation recovery rates is based on the monoparametric model developed by Gouveia et al. (2010) which relies on the so called Gorgeous Year (GY) defined as an annual vegetative cycle associated to an ideally healthy state of vegetation whose monthly means are computed by selecting the maximum value of NDVI in the pre-fire period for each month. The model is given by:

$\ln \left[\frac{y(t)}{a}\right]=-b t$

where

$y(t)=\operatorname{NDVI}(t)-\mathrm{GY}(t)$

is the so-called lack of greenness, defined by the departure of NDVI at time from the corresponding value of GY and where

$a=y(t=0)=\mathrm{NDVI}(t=0)-\mathrm{GY}(t=0)$

consisting in the value of $y$ in the first few months following the fire, represents the initial condition.

The aim of GY is to reduce inter-annual phenological variability, thereby allowing estimating the recovery rate $b$ by means of regression analysis applied to a set of monthly values of $y$. The fit of the mono-parametric model also allows estimating vegetation recovery times $\left(t_{\mathrm{R}}\right)$, that correspond to the instant when the modelled curve of vegetation recovery crosses the threshold defined as $90 \%$ of the median value in time of the spatially averaged lack of greenness over the prefire period. It must be stressed that this definition of vegetation recovery only refers to the re-establishment of pre-fire chlorophyll levels, or vegetation density (vegetation greenness). Therefore, it does not account for either the recovery of ecosystem's structure or diversity, as it does not for individual tree or species development. Throughout this work the expression vegetation recovery is only used in the above mentioned sense of vegetation greenness.

Although the methodology has proven to be adequate to monitor vegetation recovery following large wildfire events occurred during 2003 (Gouveia et al., 2010), the time-series used just covered the period 1998-2006 and therefore accounted only for 3 years following the fire season which was not long enough to evaluate the accuracy of the model's estimations. The considered period was further marked by the drought episode of 2005, one of the most severe droughts since early 20th century (Garcia-Herrera et al., 2007), which may have influenced the recovery process. Therefore, a preliminary assessment of the model accuracy was performed by applying it to the two regions analysed in Gouveia et al. (2010) using both the original 8-year dataset (1998-2006) and the extended dataset of 11-years (1998-2009) and by then comparing the recovery time estimations. 


\subsection{Model performance and robustness}

The methodology was applied to 7 additional large fire scars respecting to the 2003, 2004 and 2005 fire seasons in Portugal. The model performance was then assessed through the evaluation of the model's sensitivity to the initial condition $a$, i.e. to the lack of greenness $(y)$ at $t=0$ and to the length of the dataset. The robustness of the model to missing data was also tested. The analysis led to some adjustments, which were considered in the analysis of post-fire vegetation recovery.

\subsection{Analysis of vegetation recovery}

Finally, the methodology was applied to individual pixels of two burnt scars respecting to the 2003 and 2005 fire seasons, both located in Central Portugal. The aim of the analysis was to uncover spatial relationships and then assess the relevance of driving factors of the recovery process, especially fire damage. The difference in vegetation activity, as obtained by NDVI, during the pre- and post-fire periods, was used to estimate fire damage, instead of burn severity, since the latter definition is often associated with a large amount of factors which include the impacts on atmosphere, on soil composition, the amount of organic material consumed or by effects in vegetation such as the amount of char on shrubs, scorch height and crown scorch, tree mortality or the presence of colonizers (Jain and Graham, 2004; Miller and Thode, 2007). In order to attenuate the differences induced by the presence of several vegetation types, as well as to low levels of pre-disturbance chlorophyll (Miller and Thode, 2007), a normalized difference of pre- and post-fire mean NDVI values was used to evaluate fire damage, as given by:

$\mathrm{NDVI}_{\text {DIFF }}=\frac{\text { NDVI }_{\text {PRE }}-\mathrm{NDVI}_{\mathrm{POST}}}{\mathrm{NDVI}_{\mathrm{PRE}}+\mathrm{NDVI}_{\mathrm{POST}}}$

where NDVI PRE $_{\text {and }}$ NDVI $I_{\text {POST }}$ correspond to the mean NDVI value evaluated in May of the year of the fire event and of the following year, respectively. The evaluation of NDVI in May has the advantage of evaluating the impact of fire in the new phenological cycle, while minimizing the influence of ashes and charcoal on observations (Gouveia et al., 2010). Since NDVI PRE $>$ NDVI $_{\text {POST }}$, NDVI $_{\text {DIFF }}$ ranges between 0 and 1 and is an indicator of the degree of decrease in vegetation photosynthetic activity following the fire, i.e. of fire damage. The role played by fire damage on post-fire vegetation recovery was then assessed by performing a K-means cluster analysis on pairs of $\left\{t_{R}, \mathrm{NDVI}_{\mathrm{DIFF}}\right\}$, i.e. of pairs of recovery time and normalized difference of NDVI respecting to pixels located inside selected burnt scars.

Information about recovery time on a pixel by pixel basis may be also used to uncover systematic differences in postfire behaviour and relate them to the distinct vegetation compositions that are part of the ecosystem. This was achieved by performing a simple K-means clustering over the set $\left\{t_{R}\right\}$,
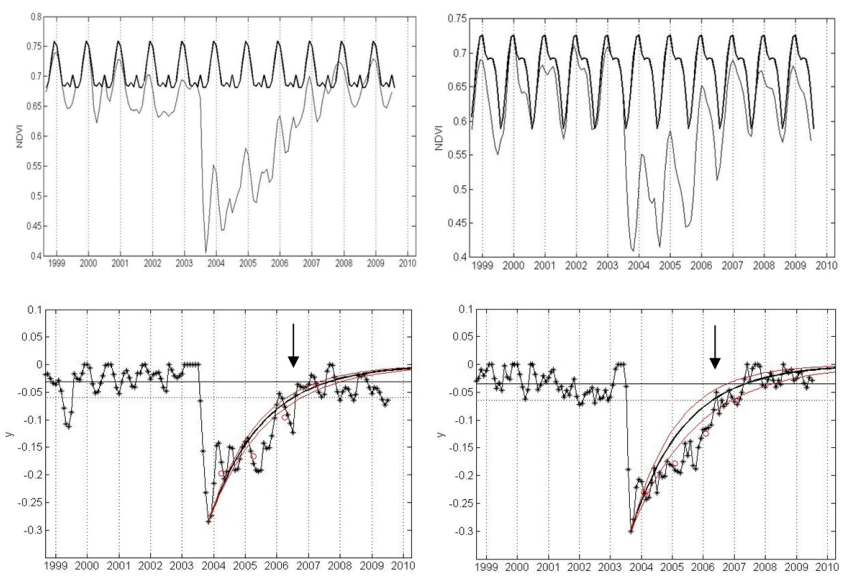

Fig. 2. Time series of monthly NDVI (grey curve) and of monthly GY (black curve) spatially averaged over RII (top left panel), and RIV (top right panel). Time series of monthly lack of greenness, $y$ (black line with asterisks) and modelled curve (solid line) of vegetation recovery, spatially averaged over RII (bottom left panel) and RIV (bottom right panel). Vertical arrows indicate the estimated recovery times of vegetation. Red curves indicate the $95 \%$ confidence limits of the regressed curve and red circles indicate the annual means of $y$. Vertical arrows indicate the estimated recovery times of vegetation.

associated to the pixels belonging to a given burnt scar. The vegetation composition of each obtained cluster was then used to analyse the dependency of vegetation recovery on land cover type.

\section{Quality assessment of the model}

\subsection{Evaluation of model accuracy}

As already pointed out, Gouveia et al. (2010) have applied the above-described mono-parametric model to a time series of NDVI covering the period from 1998 to 2006, which however was not long enough to encompass a complete recovery of vegetation. Since the present work relies on an extended 11-year time-series (1998-2009) an evaluation of the model with independent data becomes possible, which is a crucial step in validating the methodology proposed by Gouveia et al. (2010) before attempting to generalize it. Fig. 2 (top panel) presents monthly values of MVC-NDVI and GY for Regions II and IV (hereafter RII and RIV), which correspond to the regions considered in Gouveia et al. (2010). The respective $y$ time-series and modelled curves are also presented in Fig. 2 (bottom panel). In the case of RIV, the estimated recovery time, 44 months, differs by only one month from the estimated time of 43 months by Gouveia et al. (2010), and is within the respective $95 \%$ confidence interval of $[38,49]$ months. 
Table 1. Estimates $\left(t_{\mathrm{R}}\right)$ and $95 \%$ confidence intervals $\left(\mathrm{I}_{95}\left[t_{\mathrm{R}}\right]\right)$ of recovery time respecting to the fit by linear regression of the monoparametric model of vegetation recover on $y$ datasets A, B and C, in all selected Regions. Recovery times different using datasets B and C area highlighted with an $*$.

\begin{tabular}{l|cc|cc|cc}
\hline & \multicolumn{2}{|c|}{$\mathrm{A}$} & \multicolumn{2}{|c|}{$\mathrm{B}$} & \multicolumn{2}{c}{$\mathrm{C}$} \\
& $\begin{array}{c}t_{\mathrm{R}} \\
\text { (months) }\end{array}$ & $\begin{array}{c}\mathrm{I}_{95}\left[t_{\mathrm{R}}\right] \\
\text { (months) }\end{array}$ & $\begin{array}{c}t_{\mathrm{R}} \\
\text { (months) }\end{array}$ & $\begin{array}{c}\mathrm{I}_{95}\left[t_{\mathrm{R}}\right] \\
\text { (months) }\end{array}$ & $\begin{array}{c}t_{\mathrm{R}} \\
\text { (months) }\end{array}$ & $\begin{array}{c}\mathrm{I}_{95}\left[t_{\mathrm{R}}\right] \\
\text { (months) }\end{array}$ \\
\hline RI & 52 & {$[45,61]$} & 65 & {$[61,71]$} & 65 & {$[61,71]$} \\
RII & 52 & {$[48,59]$} & 39 & {$[34,44]$} & $40^{*}$ & {$[36,46]$} \\
RIII & 60 & {$[54,68]$} & 38 & {$[31,48]$} & $46^{*}$ & {$[42,50]$} \\
RIV & 43 & {$[38,49]$} & 44 & {$[39,52]$} & 44 & {$[39,52]$} \\
RV & 21 & {$[18,25]$} & 19 & {$[17,21]$} & 19 & {$[17,21]$} \\
RVI & 12 & {$[10,18]$} & 13 & {$[10,18]$} & 13 & {$[10,18]$} \\
RVII & & & 42 & {$[40,45]$} & 42 & {$[40,45]$} \\
RVIII & & & 30 & {$[28,32]$} & 30 & {$[28,32]$} \\
RIX & & & 45 & {$[42,48]$} & 45 & {$[42,48]$} \\
\hline
\end{tabular}
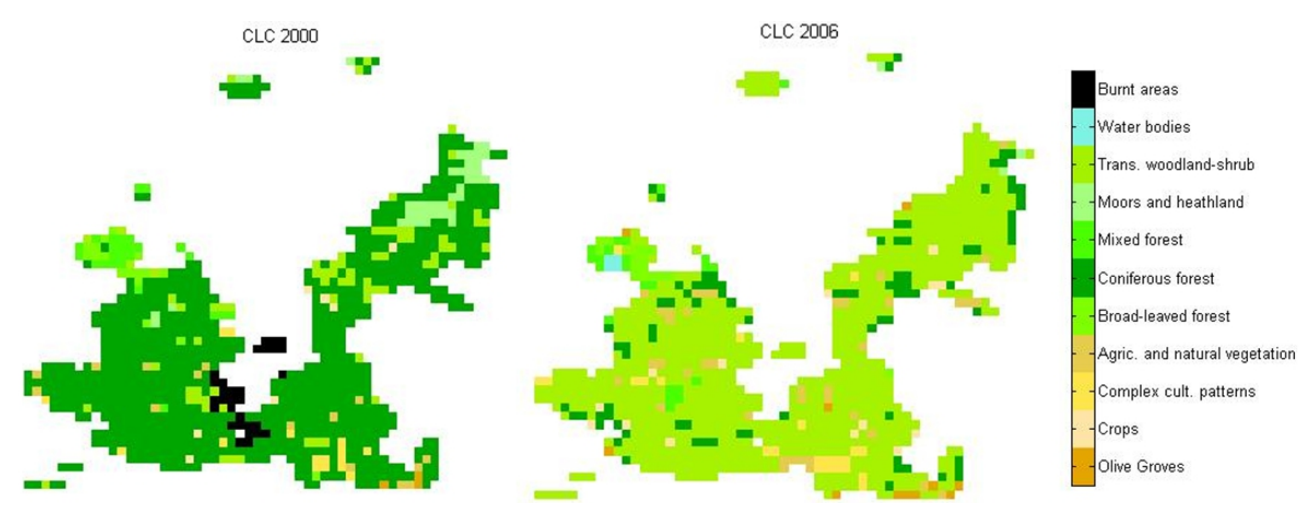

Fig. 3. Land-cover maps over the burnt scar in RII, according to CLC2000 (left panel) and CLC2006 (right panel). Class labels are shown in the colorbar.

Nevertheless, the estimated value of vegetation recovery time for RII, 39 months (Table 1), differs substantially from the estimated value of 52 months as provided by Gouveia et al. (2010) and is out of the $95 \%$ confidence interval of [48, 59] months, However, the regressed curve over the 11-year time-series seems to have been pushed due to the presence of several points with positive values located in the post-fire period. Such positive values correspond to higher levels of vegetation activity than before the fire occurrence, and this is not consistent with the definition of GY. In fact, a careful observation of NDVI time-series reveals a change of the vegetative cycle over the post-fire period, especially after 2006, as the positive values of the lack of greenness, $y$, seem to be due to a shift in the beginning of the growing season. It is also worth noting that maximal values of NDVI reached over the vegetative cycle following the recovery, especially from 2006 onwards, are lower than before the fire. Vegetation dynamics after 2007 may therefore indicate an evolution towards a distinct vegetative cycle, as the growing season starts earlier, and the second peak of the vegetative cycle tends to disappear. Since NDVI does not provide information about the ecosystem's composition or structure, the assessment of changes in vegetation composition was based on the comparison of data of land-cover from Corine Land-Cover 2000 and Corine Land-Cover 2006 for the burnt scar (Fig. 3). It is clear that land-cover composition has drastically changed, as transitional woodland-shrub has occupied the majority of the areas classified as coniferous forest or burnt areas in 2000.

\subsection{Model performance analysis}

\subsubsection{Sensitivity to the initial conditions}

The simple definition of $a$ as given by the value of the lack of greenness in the first few months after fire (Gouveia et al., 2010) may lead to a poor fit of the regressed curve in those areas where the minimal value of $y$ is reached several months after the fire event. This is perfectly clear when the model is applied to the burnt scar in RVII, as shown in Fig. 4 (red ellipse, left panel). This is due to vegetation mortality which may occur in the post-fire period, especially during 

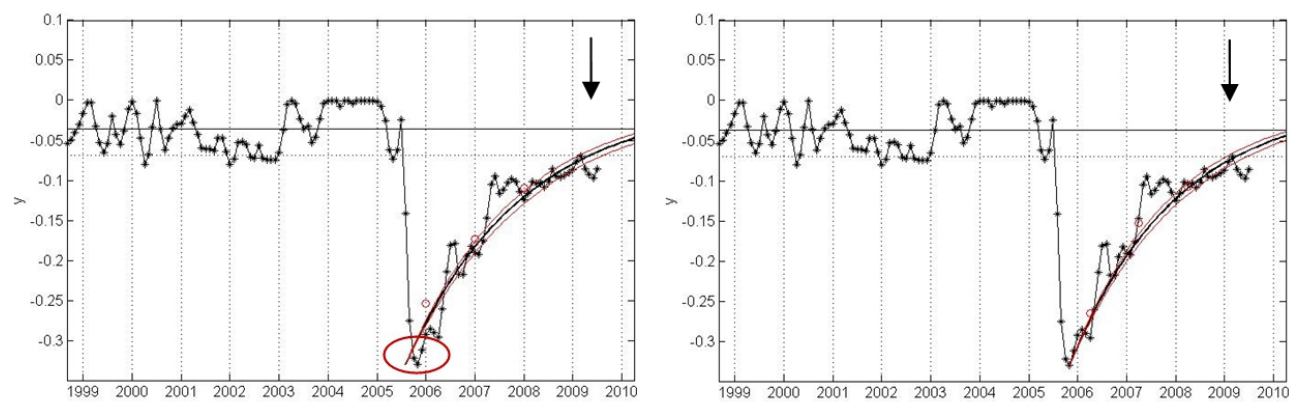

Fig. 4. Time-series of observed (black line with asterisks) and modelled (black line) time-series of lack of greenness, $y$, averaged over the burnt scar on RVII without correction (left panel) and corrected (right). The red ellipse (left panel) highlights the maladjustment of the uncorrected modelled curve of vegetation recovery. Vertical arrows indicate the estimated recovery times of vegetation.

the following autumn (De Luís et al., 2001). It seems, thus, reasonable to assume that recovery starts just after the minimum is reached, within the period ranging from the beginning of the fire season of the respective year to the beginning of the fire season of the following year. Taking this fact into account the value of $a$ (i.e. of $y(t=0)$ ) was calculated by choosing the month corresponding to the minimal value of the lack of greenness $(y(t))$ over a period ranging from April, the beginning of the fire season, of each year until March of the following year. As shown in Fig. 4 (right panel), this approach provided a better adjustment of the model to the observed values (red circles), especially to the first months of recovery, leading to considerable differences in recovery times and to a reduction in the width of the $95 \%$ confidence interval. Obtained estimated times of vegetation recovery $\left(t_{\mathrm{rR}}\right)$ and of respective $95 \%$ confidence intervals $\left(\mathrm{I}_{95}\left[t_{\mathrm{R}}\right]\right)$ are $t_{\mathrm{R}}=47$ months, $\mathrm{I}_{95}\left[t_{\mathrm{R}}\right]=[44,50]$ months for uncorrected modelling and $t_{\mathrm{R}}=42$ months, $\mathrm{I}_{95}\left[t_{\mathrm{R}}\right]=[40,45]$, after correction. This adjustment was tested for all the considered regions with satisfactory results.

It is worth stressing that small differences (of one or two months) in the starting point may lead to substantial variations (of several months) in the estimated recovery times. On the other hand, the adjustment of the starting point of the modelled time-series to the minimal value of observed lack of greenness between two fire seasons generally led to narrower $95 \%$ confidence intervals. Therefore, the described adjustment in the process of estimating the value of $a$ was adopted in the present study of vegetation recovery.

\subsubsection{Sensitivity to the temporal length of the input data}

The post-fire vegetation recovery model was applied to Regions I to IX using as input 3 sets respecting to distinct periods: (A) from September 1998 to August 2006, i.e. the same time-series that was used in Gouveia et al. (2010); (B) from September 1998 to August 2009, corresponding to the extended 11-year time-series; (C) as in (B) but with the additional criterion that consists in excluding all the months following the first month with positive lack of greenness, $y$, since these values may correspond to a distinct vegetative cycle and introduce phenological variability. It is worth noting that the additional criterion was only applied if there are two or more months with positive $y$ in the post-fire period, a restriction that was introduced in order to ignore situations with just one month with positive $y$, since that single observation does not imply a modification of the vegetative cycle.

Table 1 provides an overview of the estimates of recovery time as obtained through the application of the model to all the regions considered when using datasets $\mathrm{A}, \mathrm{B}$ and $\mathrm{C}$. When considering the set of six cases (RI to RVI) that allowed using dataset $\mathrm{A}$, in half of the regions (RIV to RVI), the model leads to very similar estimates when either using dataset A or the longer dataset B. In fact, in the cases of RIV to RVI, the estimated recovery times respecting to dataset $\mathrm{B}$ fall within the $95 \%$ confidence intervals obtained when using dataset $\mathrm{A}$ and differ only by one or two months. Because dataset $\mathrm{A}$ encompasses less than one year of recovery for fires occurred in 2005, only datasets B and C were used in the case of Regions VII to IX. On the other hand, in seven out of the nine considered regions, use of dataset $\mathrm{C}$ does not lead to different results from those obtained with $\mathrm{B}$, the exceptions being RII and especially RIII, where the considerably narrower $95 \%$ confidence interval provides an indication of a better performance of the model.

The most conspicuous differences in the estimates may be found in Regions I, II and III, the latter presenting large differences when using the three datasets and the remaining two when using dataset $\mathrm{A}$ and dataset B (or C). In the case of RI, the fit of the model to dataset A leads to an estimate of recovery time that is 14 months shorter than the ones obtained when fitting the model to datasets $\mathrm{B}$ or $\mathrm{C}$ (Table 1). A close inspection of the 11-year time-series of lack of greenness $y$ for RI (Fig. 5, top panel) indicates that, in fact, vegetation did not recover completely, since values observed from 2007 onwards oscillate about a stagnation stage that is well below the pre-defined threshold of $90 \%$ of the median (that was assumed to represent full recovery of vegetation). Since such stage of stagnation does not seem to have happened 

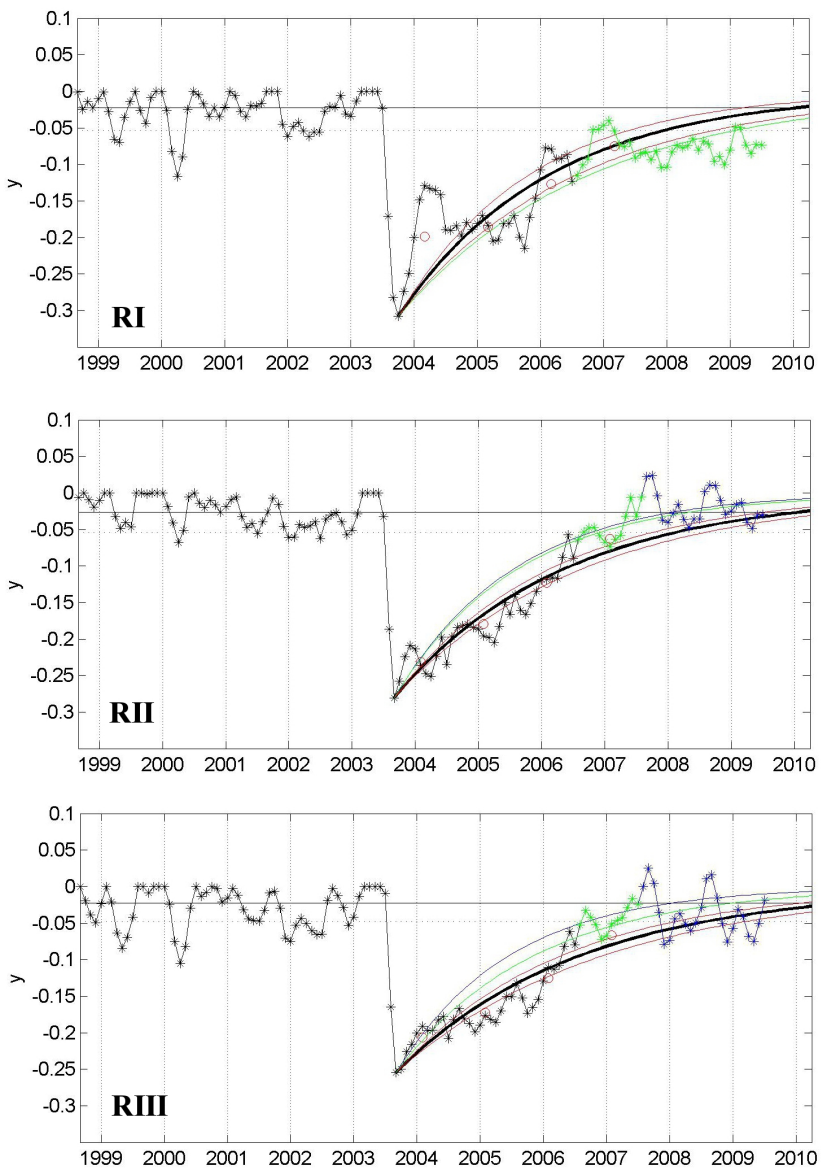

Fig. 5. As in Fig. 4 but respecting to RI, RII and RIII (top, central and bottom panels, respectively) when using datasets A (black line with asterisks, black modelled curve), B (black, green and blue line with asterisks, blue modelled curve) and C (black and green line with asterisks, green modelled curve). Red lines indicate the $95 \%$ confidence limits of the regressed curve A. In the case of RI, the blue and green modelled curves coincide.

during the pre-fire period, where a few months with values of $y$ markedly below $90 \%$ of the median may be observed in 2000 (three cases) and during the two droughts events of 1998/99 and 2001/02 (Gouveia et al., 2009), there seems to have been a disturbance of vegetation activity. Unfortunately no information was found that would allow finding the reasons for this disruption of vegetation recovery, which can be either due to natural events or to human intervention. The case of RII was already addressed in Sect. 4.1 and it may be recalled that discrepancies are to be attributed to changes in the ecosystem, namely to the fact that a new type of vegetation replaced the one existing before the fire event (Fig. 3). The already discussed leverage effect of the positive values $y$ when fitting the model to the longer datasets B and C may be again appreciated by comparing (Fig. 5, central panel), the black regressed curve (obtained with the shorter 8-year dataset A) with the green or the blue ones (obtained with the longer datasets B and C). Finally, in the case of RIII, the fit of the model using dataset A leads to an estimated recovery time of 60 months which is 22 months longer than the one obtained using the full dataset $\mathrm{B}\left(t_{\mathrm{R}}=38\right.$ months) and 14 months longer than estimated time ( $t_{\mathrm{R}}=46$ months) when using dataset $\mathrm{C}$ (Table 1). Taking into account the major role of water availability in primary production, this result may be attributed to the effect of the severe drought of $2004 / 05$, which may have delayed the regeneration process. On the other hand, the marked differences obtained in the estimates when using datasets B and C (Table 1) reflect a possible leverage effect of the few strongly positive values of lack of greenness $y$ that may be observed in the post-fire period (Fig. 5, bottom panel).

\subsubsection{Sensitivity to missing data}

In order to evaluate the sensitivity of the model to the occurrence of a long-lasting perturbation (e.g. droughts) or to missing data (a relatively common situation in many remotesensed time series), its robustness was tested by artificially removing several months of data. Although the testing procedure was applied to the chosen set of burnt areas, it is more instructive to provide a full description of obtained results to a single burnt area, namely to RVIII that presents an undisrupted recovery process and where the good fit of the model provides an indication of a very satisfactory adjustment. As shown in Table 1 the baseline estimated recovery time for this area is $t_{\mathrm{R}}=30$ months (with $\mathrm{I}_{95}\left[t_{\mathrm{R}}\right]=[28,32]$ ).

Twelve values were therefore removed from the timeseries $y$, since droughts and other severe natural disturbances, may typically last up to about one year. The values were therefore set to missing data according to the four following criteria:

1. Missing values are distributed randomly in the time-series within the period following the fire event;

2. Data is missing immediately after the fire event;

3. Missing data occur during the regeneration period;

4. Data is missing immediately after recovery is achieved.

An overview of obtained results is provided in Table 2 and it may be observed that in general deviations from the baseline recovery time are rather small. In fact, the highest values of deviations represent just 1 month departures from the reference recovery time when using criteria a) and c), but even in these cases deviations fall within the respective $95 \%$ confidence interval. It may be noted that, when assessing the effect of randomly missing files, several tests were performed leading to slightly different results, with departures in estimated recovery times of the order of one or two months, but always within the range of the baseline $95 \%$ confidence interval. Finally, in the case of the remaining criteria, b) and d), no differences were found, neither in the estimates nor in the corresponding $95 \%$ confidence intervals. 
Table 2. Vegetation recovery time $\left(t_{\mathrm{R}}\right)$ and respective $95 \%$ confidence interval $\left(\mathrm{I}_{95}\left[t_{\mathrm{R}}\right]\right)$, in months, as estimated by the monoparametric vegetation recovery model for the burnt scar located in RVIII, for the complete dataset (baseline) and with missing removed according to criteria a) to d).

\begin{tabular}{lccc}
\hline Missing data (months) & $t_{\mathrm{R}}$ (months) & $\mathrm{I}_{95}\left[t_{\mathrm{R}}\right]$ (months) \\
\hline & Baseline & 30 & {$[28,32]$} \\
a) & Random & 29 & {$[27,31]$} \\
b) & {$\left[\mathrm{t}_{0}+1, \mathrm{t}_{0}+12\right]$} & 30 & {$[28,32]$} \\
c) & {$\left[\mathrm{t}_{0}+13, \mathrm{t}_{0}+24\right]$} & 31 & {$[29,32]$} \\
d) & {$\left[\mathrm{t}_{0}+20, \mathrm{t}_{0}+31\right]$} & 30 & {$[28,32]$} \\
\hline
\end{tabular}

\section{Assessment of post-fire vegetation behaviour}

\subsection{Characterization of selected regions}

Results obtained in the previous section provide a strong indication that the mono-parametric model developed by Gouveia et al. (2010) is able to provide adequate estimates of recovery times of vegetation, provided the regeneration process is not disrupted by any extreme natural event or by human intervention and time-series of NDVI of moderate extent are available. In case of disruption of the regeneration process, the recovery process no longer tends to follow a smooth exponential growth (as given by Eqs. 1 and 2) and therefore the proposed model cannot be applied in a simply direct way. Moreover, even when there is no evidence of disruption, care must be taken in the setting of both the initial conditions (Sect. 4.2.1) and on the choice of the temporal window of the time series of lack of greenness (Sect. 4.2.2). The model has also proven its robustness against missing data and is, therefore, expected to provide good estimations of recovery times even when the time-series presents discontinuities.

It is therefore to be expected that the proposed model of vegetation recovery has a good potential to be applied in the analysis of vegetation dynamics, in particular in the study of spatial patterns and in the assessment of the influence of biological and environmental factors on post-fire vegetation recovery. In order to assess such potential, two burnt areas were selected, respectively located in RIII and RVII (Fig. 1) and respecting to the fire seasons of 2003 and 2005. The burnt area located in RIII has an extent of about 41300 ha and, according to CLC2000 (Table 3), is mainly occupied by coniferous forest $(71 \%)$ and transitional woodland-shrub $(16 \%)$. The second area is smaller, with about 25700 ha of extent, and is also occupied by coniferous forest and transitional woodland-shrub, although in different proportions ( $35 \%$ and $45 \%$, respectively). According to the ANF database, the coniferous forest in both regions is mainly composed by Pinus pinaster species.

The marked decrease in NDVI following the fire event is clearly visible in both time-series of lack of greenness $y$ aver-
Table 3. Land-cover composition in 2000 and 2006 of RIII and RVII based on information, from Corine Land-Cover datasets.

\begin{tabular}{lccc}
\hline & \multicolumn{2}{c}{ RIII } & RVII \\
& $\begin{array}{c}\text { Areal cover } \\
2000(\%)\end{array}$ & $\begin{array}{c}\text { Areal cover } \\
2006(\%)\end{array}$ & $\begin{array}{c}\text { Areal cover } \\
2000(\%)\end{array}$ \\
\hline Coniferous Forest & 71 & 16 & 35 \\
Transitional Woodland-Shrub & 16 & 68 & 45 \\
Other & 13 & 16 & 20 \\
\hline
\end{tabular}

aged over RIII and RVII (Fig. 6). It is worth pointing out that the minimum of $y$ for RVII was reached only in November 2005 , i.e. three months following the fire occurrence, presenting a lower value of $y$ than the one for RIII (respectively about 0.33 and 0.25 ). The two areas present markedly distinct behaviours. In the case of RIII, vegetation recovery appears to have been affected by drought, the slow recovery rates during 2004 and 2005 being followed by a period of fast growth from September 2005 to 2007. On the contrary, the time-series of $y$ averaged over RVII suggests an irregular regeneration process, marked by a fast growth in the first year, followed by a long period of near-stagnation during which most monthly values stay well below the recovery threshold.

In order to study spatial variability of regeneration, the model was fitted to time series of $y$ for all individual pixels of each region. A close inspection of the spatial distribution of recovery times (Fig. 7) reveals marked differences between the two regions, RIII presenting slower recovery times, with several pixels associated to recovery times above 60 months, as opposed to RVII that presents few pixels with recovery time above 60 months and a relatively large number with recovery times below 20 months. In spite of the high variability observed, results present spatial consistency, as estimated recovery times tend to aggregate in homogenous patches, suggesting the existence of distinct physical and environmental conditions. In fact, it is possible to distinguish in RIII two large patches associated with high recovery times (above 60 months), respectively located in the northwest and in the southeast of the scar, as well as one patch associated with low recovery times (below 20 months), located near the western boundary. In the case of RVII, one large patch located in the north-east presents recovery times above 50 months whereas another one, located along the boundary, displays recovery times below 15 months.

\subsection{The role of fire damage}

The spatial distributions of the normalized difference of NDVI between May 2004 and May 2003 for RIII and between May 2005 and May 2004 for RVII are shown in Fig. 8. As suggested by initial conditions (Fig. 6), RVII has markedly been more severely damaged by fire, as several pixels present normalised differences above 0.3 , whereas in RIII no pixels associated to such high differences are observed. 

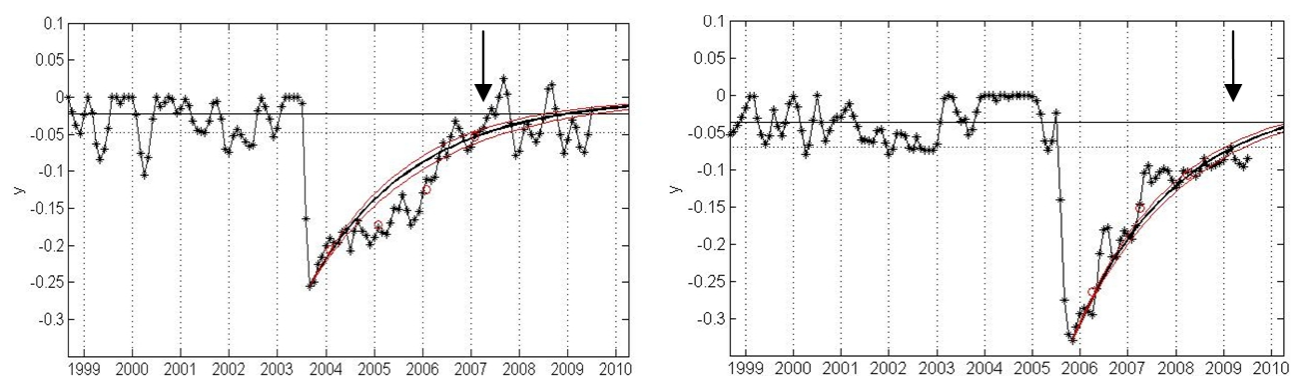

Fig. 6. As in Fig. 3 but respecting to burnt scars in RIII (left panel) and RVII (right panel).

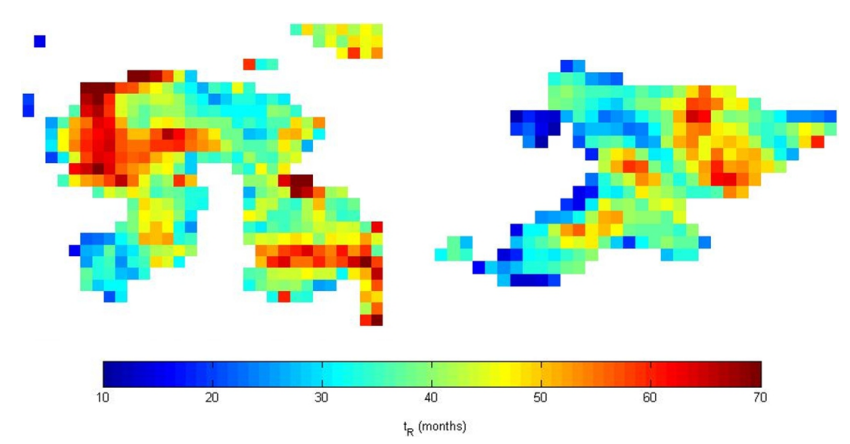

Fig. 7. Spatial distribution of recovery times, in months, over RIII (left panel) and RVII (right panel).

On the other hand, and for both regions, the spatial distribution of NDVI DIFF (Fig. 8) presents similar features to those observed in the spatial distribution of recovery times (Fig. 7). In the case of RIII, a large patch, corresponding to values of $\mathrm{NDVI}_{\text {DIFF }}$ between 0.2 and 0.3 may be observed in the northwest of the area, extending to the south. Another patch, corresponding to $\mathrm{NDVI}_{\mathrm{DIFF}}$ values around 0.2 , may be observed in the southeast of the scar. For RVII a very large patch extending from the north-east to the south-west along the northern region of the scar presents high values of

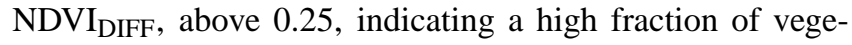
tation highly damaged by fire. Some pixels located along the western boundary present very low values of NDVI DIFF, below 0.05 , possibly due to contamination by non-burnt pixels in the neighbourhood. The fact that spatial patterns of NDVI DIFF distribution are very similar to the spatial distribution of recovery times, suggests the existence of a physical relationship between recovery time and fire damage, which must be checked cautiously.

Further insights on the relationships between recovery time and fire damage may be obtained by applying a $\mathrm{K}$ means cluster analysis to the pairs $\left\{t_{\mathrm{R}}, \mathrm{NDVI}_{\mathrm{DIFF}}\right\}$ for pixels belonging to the burnt scars associated to the two main land-cover classes (i.e. coniferous forest and transitional woodland-shrub). Figure 9 presents, for RIII (left panel) and RVII (right panel), the dispersion diagrams (top panels) of the three clusters obtained, as well as the spatial distribution

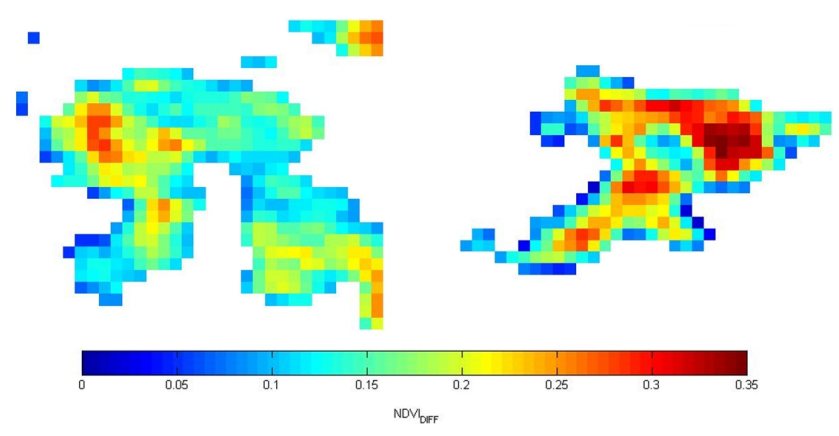

Fig. 8. Spatial distribution of normalized difference of NDVI mean values between May before the fire occurrence and May in the year following each fire season, over RIII (left panel) and RVII (right panel).

of pixels corresponding to each cluster (bottom panels). Dispersion diagrams suggest a monotonic relationship between $t_{\mathrm{R}}$ and $\mathrm{NDVI}_{\mathrm{DIFF}}$ for both regions, as recovery times increase

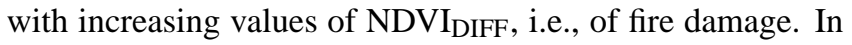
the case of RIII, the mean recovery times associated to each cluster are 36, 45 and 54 months, covering 34, 36 and $30 \%$ of the area, respectively. Lower mean recovery times were found in RVII where the mean recovery times associated to each cluster are 22, 37 and 46 months, representing $22 \%$, $41 \%$ and $37 \%$ of the area, respectively. Although a moderate superposition of interquartile ranges of $t_{\mathrm{R}}$ may be observed in the obtained clusters of RIII, the same does not happen in RVII where clusters present clearly distinct variability ranges both in $t_{\mathrm{R}}$ and NDVI DIFF. Finally it is worth noting that, in both regions, the spatial distribution of the pixels belonging to the identified clusters is coherent with the homogenous patches that were also observed in the distributions of $t_{\mathrm{R}}$ (Fig. 7) and of NDVI DIFF (Fig. 8).

The above discussed features of the identified clusters in pairs of $\left\{t_{\mathrm{R}}, \mathrm{NDVI}_{\mathrm{DIFF}}\right\}$ strongly indicate the existence of physical relationships between the two variables. Vegetation recovery seems, therefore, to be partially determined in both regions by the degree of fire damage in vegetation cover. This result is further consistent with the fact that the ecosystems of both regions are mostly composed by Pinus pinaster, whose 

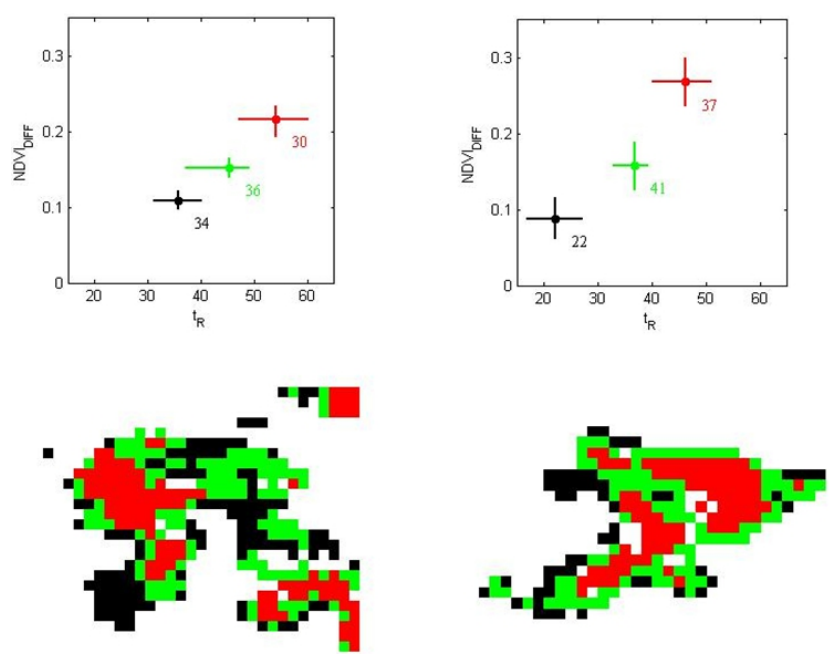

Fig. 9. Dispersion diagrams (top panels) and spatial distribution (bottom panels) of centroids, identified by distinct colours, as obtained by the K-means cluster analysis performed on the pair $\left\{t_{\mathrm{R}}\right.$, NDVI $_{\text {DIFF }}$ over RIII (left panels) and RVII (right panels), for the two main land-cover classes. Coordinates of the centroids are identified by circles in the dispersion diagrams; horizontal and vertical bars indicate interquartile ranges. Integer numbers near each centroid indicate the fraction of areal cover $(\%)$ by each cluster.

regeneration is particularly affected by fire intensity and burn severity. In fact, tree survival during the fire, as well as postfire germination of seeds, seem to be determined by the exposure to certain temperature thresholds (Pérula et al, 2003; Fernandes and Rigolot, 2007).

Results obtained further support the proposed use of

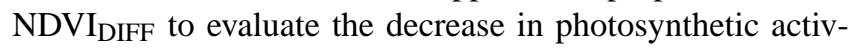
ity following fire events and therefore its use as an indicator of burn severity in what concerns the effects of fire on vegetation. Furthermore, the definition of a NDVI normalized difference index to estimate fire damage overcomes some of the problems associated to other differentiated indices, since the dependency on pre-fire vegetation conditions is eliminated.

\subsection{The role of land cover}

As pointed out in 3.1.4, estimates of time recovery on a pixel by pixel basis may be used to uncover the dependency of vegetation recovery on the distinct compositions of vegetation that integrate the burnt ecosystems of RIII and RVII. A $\mathrm{K}$-means cluster analysis was accordingly performed on the set $\left\{t_{R}\right\}$ of pixel estimates of recovery time of each burnt scar. The vegetation composition before and after the fire event was then evaluated for each cluster, based on information provided by CLC2000 and CLC2006. It is worth noting that CLC2006 dataset was not used to evaluate vegetation composition over RVII, burnt in 2005, because it would probably be misleading. Results are summarized in Table 4 for RIII and RVII and there are similarities in vegetation recover in the two regions that are worth being noted. Both regions present one cluster with a centroid of the order of two years (32 and 21 months, in RIII and RVII, respectively), another one of about three to four years (45 and 36 months, respectively) and a third one of more than four years (63 and 51 months, respectively) following the fire event.

The systematically higher values of recovery time for the centroids in RIII may be due to the effect of the 2005 drought event. Nevertheless, the distinct recovery times that are observed in the overall regeneration process may indicate the existence of specific traits of vegetation. In fact, there are marked differences between the vegetation composition of each centroid and the overall composition (Table 3) of the corresponding scar, an indication of the distinct behaviour of coniferous forest and transitional woodland-shrub. In RIII, the coniferous forest represents $83 \%$ of the cluster with an intermediate mean recovery time ( $t_{\mathrm{R}}=45$ months), a fraction considerably higher than the fraction of the same land-cover type over the region $(71 \%)$. On the contrary, transitional woodland-shrub just represents $8 \%$ of the same cluster, half the amount of the corresponding coverage over the entire region $(16 \%)$. For the two remaining clusters with shorter and longer mean recovery times (32 and 63 months) the areal fractions of transitional woodland-shrub are $23 \%$ and $24 \%$, are well above the overall value of $16 \%$, whereas coniferous forest just represents $62 \%$ and $63 \%$, respectively. In RVII, major differences may be also observed between land-cover types, as coniferous forest represents $63 \%$ of the cluster with longer recovery times, markedly above the corresponding fraction of the overall area (35\%), whereas for the remaining centroids, with low and intermediate mean recovery times, coniferous just represent 22 and $24 \%$, respectively. The opposite behaviour may be observed in these two clusters for transitional woodland-shrub, which presents areal coverages of 51 and $54 \%$ which are above the overall fraction (45\%), contrasting with the small amount of $22 \%$ that characterizes the third cluster with the longer mean recovery time.

Results for RVII suggest that vegetation recovery tends to be quicker for transitional woodland-shrub while coniferous forests tend to recover more slowly, which is consistent with the distinct plant traits that characterize each vegetation type, although results may also be influenced by the recovery of forest understory, especially in the first months following fire. Mediterranean dwarf/shrub vegetation is in fact well adapted to fire, being composed by many species of resprouters which recover very rapidly after fire events. On the contrary, coniferous rely on post-fire seed germination to recover after fire, a process that requires more time. This is however not the case in RIII where the cluster associated to the longest recovery time (63 months) presents a land cover composition very similar to the cluster with the shortest recovery time (32 months). The contradiction is nevertheless apparent when one takes into consideration the land cover composition that developed during the recovery process. In order to evaluate whether the faster recovery of transitional 
Table 4. Centroids and land-cover composition of the three clusters as identified by K-means performed on estimated values of recovery time of pixels in burnt scars of RIII and RVII from Corine Land-Cover datasets.

\begin{tabular}{lccccc}
\hline & \multicolumn{2}{c}{ RIII } & & \multicolumn{2}{c}{ RVII } \\
& $\begin{array}{c}\text { Centroid } \\
t_{\mathrm{R}} \\
(\text { months })\end{array}$ & $\begin{array}{c}\text { Areal } \\
\text { cover } \\
2000(\%)\end{array}$ & $\begin{array}{c}\text { Areal } \\
\text { cover } \\
2006(\%)\end{array}$ & $\begin{array}{c}\text { Centroid } \\
t_{\mathrm{R}} \\
(\mathrm{months})\end{array}$ & $\begin{array}{c}\text { Areal } \\
\text { cover } \\
2000(\%)\end{array}$ \\
\hline Coniferous forest & 32 & 62 & 9 & 21 & 22 \\
Transitional woodland-shrub & & 23 & 66 & & 51 \\
Other & & 15 & 25 & & 27 \\
\hline Coniferous forest & 45 & 83 & 17 & 36 & 24 \\
Transitional woodland-shrub & & 8 & 67 & & 54 \\
Other & 63 & 64 & 16 & & 22 \\
\hline Coniferous forest & & 24 & 56 & & 63 \\
Transitional woodland-shrub & & 12 & 28 & & 25 \\
Other & & & & & 12 \\
\hline
\end{tabular}

woodland-shrub was indeed associated to changes in ecosystem composition, CLC2000 (pre-fire) and CLC2006 (postfire) data for RIII were compared, as shown in Table 3. For RIII, the area occupied by coniferous dramatically decreased from $71 \%$ in 2000 to $16 \%$ in 2006, 25 while transitional woodland-shrub increased more than four times from 16 to $68 \%$. Additionally, the analysis of vegetation composition of recovery time clusters (Table 4) indicates steeper increase in transitional woodland-shrub areal coverage in the centroids corresponding to lower and intermediate mean recovery time, especially in the latter, where areal coverage is more than 8 times higher in 2006 than in 2000. The area appears to have suffered a dramatic change in composition of the ecosystem, as coniferous forest was replaced by transitional woodland-shrub after the fire, a result that supports those obtained in the study of the dependence of recovery time with vegetation type. Results are further consistent with previous studies (Naveh, 1975; Pérula et al., 2003; Viedma et al., 2006) documenting the trend for domination of dwarf/shrub vegetation following fire events, due to its rapid regeneration process. However, it may be noted that the study should be complemented with a long-time monitoring in order to evaluate whether these changes are persistent or correspond to a state of transition (Malkinson et al., 2011; Silva et al., 2011).

\section{Conclusions and final remarks}

The present work relied on the mono-parametric model of vegetation recovery developed by Gouveia et al. (2010). The overall quality of the model was assessed using a longer NDVI time series than the one used in the previous study and some corrective procedures were then introduced leading to improvements in terms of performance and robustness of the model. The model has shown to be especially sensitive to the setting of the initial conditions (i.e. the choice of the starting monthly value of lack of greenness following the fire) which has proven to be determinant for a correct fit of the model to the time-series of lack of greenness. The sensitivity of the model to the temporal length of the input data was also evaluated. The model has proven to be able to provide good estimations of vegetation recovery times with time-series of moderate length, unless the regeneration process is disrupted by natural or human disturbances or in case the ecosystems' composition changes dramatically after the fire event. It was finally shown that the model appears to be robust to missing data, providing generally good estimations of recovery times despite the existence of discontinuities in the dataset, unless the regeneration process is disrupted. Nevertheless, the application of the model must be always performed carefully since the disturbances in vegetation behaviour may lead to misleading results.

Two large burnt scars were selected from the 2003 and 2005 fire seasons in order to study thoroughly post-fire vegetation recovery, namely by assessing its spatial variability and then identifying determinant factors of the regeneration process. Results revealed a coherent distribution of recovery times forming homogenous patches which indicated the existence of distinct physical and environmental conditions. Fire damage was identified as a main driving factor of vegetation recovery for both regions, which is consistent with the fact that, for Pinus pinaster, both tree survival during the fire and post-fire germination of seeds seem to be determined by the exposure to certain temperature thresholds (Pérula et al., 2003; Fernandes and Rigolot, 2007). Distinct recovery rates for different vegetation types were uncovered through the assessment of land-cover composition of three identified clusters of recovery times. Transitional woodland-shrub presents shorter recovery times, while coniferous tend to recover more slowly. The result was confirmed by means of CLC2000 and 
CLC2006 datasets for the scar in RIII, which revealed that the fire event homogenized the composition of the ecosystem since most of the coniferous forests were replaced by transitional woodland-shrub. The different rates of recovery for each vegetation types lead to a dwarf/shrub domination of ecosystems in the first months of recovery, in agreement with results from previous studies (Naveh, 1975; Pérula et al. 2003; Viedma et al., 2006). Results obtained for fire damage and pre-fire land cover stress the need of integrated studies where post-fire vegetation recovery is viewed as resulting from a combination of factors that include pre-fire vegetation composition, fire regime, and environmental conditions such as climate and landscape structure.

The overall consistency of the results obtained support the adequacy of the proposed methodology to evaluate post-fire vegetation behaviour, as well as to estimate recovery times and evaluate the influence of physical and phenological factors on the dynamics of regeneration. In this respect, the simplicity and the robustness of the methodology is worth being emphasized, given the fact that the model relies on a single parameter that may be estimated by simple linear-regression, thus avoiding the need of defining control plots and just requiring NDVI time-series of moderate length and coarse resolution.

Acknowledgements. This work was partly supported by the EU 7th Framework Program (FUME) contract number 243888. The work was also partly supported by the Portuguese Science Foundation (FCT) through project FLAIR (PTDC/AAC-AMB/104702/2008). Ana Bastos was partially funded by FCT (Grant PTDC/AACAMB/104702/2008). The NDVI dataset was kindly supplied by VITO database (http://free.vgt.vito.be). We are grateful to ANF for providing the burnt map for Portugal. The CLC2006 map was kindly provided by the European Environment Agency.

Edited by: M. Marconcini

\section{References}

Arianoutsou, M. and Ne'eman, G.: Post-fire regeneration of natural Pinus halepensis forests in the east Mediterranean Basin, in: Ecology, biogeography and management of Pinus halepensis and P. brutia forest ecosystems in the Mediterranean Basin, edited by: Ne'eman, G. and Trabaud, L., Backhuys, Leiden, NL, 269-290, 2000.

Calvo L., Santalla S., Marcos E., Valbuena L., Tárrega R., and Luis E.: Regeneration after wildfire in communities dominated by Pinus pinaster, an obligate seeder, and others dominated by Quercus pyrenaica, a typical resprouters, Ecol. Manage., 184, 209223, 2003.

Calvo L., Tárrega R., Luis E., Valbuena L., and Marcos E.: Recovery after experimental cutting and burning in three shrub ecosystems situated in a climatic gradient, Plant Ecol., 180, 175-185, 2005.
Catry, F. X., Rego F., Moreira F., Fernandes P. M., and Pausas J. G.: Post-fire tree mortality in mixed forests of central Portugal, Forest Ecol. Manage., 260, 1184-1192, 2010.

Cerdà, A.: Changes in overland flow and infiltration after a rangeland fire in a Mediterranean scrubland, Hydrol. Process., 12, 1031-1042, 1998.

Cerdà, A. and Doerr, S. H.: The influence of vegetation recovery on soil hydrology and erodibility following fire: an eleven year investigation, Int. J. of Wildland Fire, 14(4), 423-437, 2005.

Chuvieco, E., Aguado, I, Yebra, M, Nieto, H., Salas, J., Martín, M. P., Vilar, L., Martínez, J., Martín, S., Ibarra, P., de la Riva, J., Baeza, J., Rodríguez F., Molina J. R., Herrera, M. A., and Zamora, R.: Development of a Framework for fire risk assessment using remote sensing and geographic information system Technologies, Ecol. Model., 221, 46-58, 2010.

De Luís, M., García-Cano, M. F., Cortina, J., Raventós, J., González-Hidalgo, J. C. and Sánchez, J. R.: Climatic trends, disturbances and short-term vegetation dynamics in a Mediterranean shrubland, Forest Ecol. Manage., 147, 25-37, 2001.

De Luís, M., Gonzales-Hidalgo, J. C., and Raventós, J.: Effects of fire and torrential rainfall on erosion in a mediterranean gorse community, Land degrade. Delevop., 14, 203-213, 2003.

De Luis, M., Baeza, M. J., Raventos, J. and Gonzales-Hidalgo, J. C.: Fuel characteristics and fire behavior in mature Mediterranean gorse shrub land, Int. J. of Wildland Fire, 13, 79-87, 2004.

De Santis, A. and Chuvieco, E.: Burn severity estimulation from remotely sensed data: Performance of simulation versus empirical models, Rem. Sens. Environ., 108, 422-435, 2007.

DeBano, L. F., Neary, D. G., and Folliott, P. F.: Fire's Effects on Ecosystems, John Wiley and Sons, New York, 333 pp, 1998.

DGRF: Incêndios Florestais - Portugal, Ministério da Agricultura, Pescas e Florestas (in Portuguese), 2008.

Díaz-Delgado, R. and Pons, X.: Spatial patterns of forest fires in Catalonia (NE of Spain) along the period 1975-1995. Analysis of vegetation recovery after fire, Forest Ecol. Manage., 147, 6774, 2001

Díaz-Delgado, R., Salvador, R., and Pons, X.: Monitoring of plant community regeneration after fire by remote sensing, in: Fire management and landscape ecology, edited by: Traboud, L., Int. Association of Wildland Fire, Fairfield, WA , 315-324, 1998

Epting, J. and Verbyla, D.: Landscape-level interactions of prefire vegetation, burn severity, and postfire vegetation over a 16-year period in interior Alaska, Can. J. For. Res., 35, 1367-1377, 2005.

Fernandes, P. M. and Rigolot, E.: The fire ecology and management of maritime pine (Pinus pinaster Ait.), Forest Ecol. Manage., 241, 1-13, 2007.

Ferran A., Delitti W., and Vallejo, V. R.: Effects of different fire recurrences in Quercus coccifera communities of the Valencia region, Proceedings of the III International Conference on Forest Fire Research, Vol. 2, 1555-1569, Coimbra, 1998.

Fox, D. M., Maselli, F., and Carrega, P.: Using SPOT images and field sampling to map burn severity and vegetation factors affecting post forest fire erosion risk, Catena, Elsevier, 75, 326-335, 2008.

Garcia-Herrera, R., Paredes, D., Trigo, R. M., Trigo, I. F., Hernández, E., Barriopedro, D., and Mendes, M. A.: The Outstanding 2004/05 Drought in the Iberian Peninsula: Associated Atmospheric Circulation, J. Hydrometeorol., 8, 483-498, 2007.

Goetz, S. J., Fiske, G. J., and Bunn, S. G.: Using satellite time-series 
data set to analyze fire disturbance and forest recovery across Canada, Remote Sens. Environ., 101, 352-365, 2006.

Gouveia, C., Trigo, R. M., and DaCamara, C. C.: Drought and vegetation stress monitoring in Portugal using satellite data, Nat. Hazards Earth Syst. Sci., 9, 185-195, doi:10.5194/nhess-9-1852009, 2009.

Gouveia, C., DaCamara, C. C., and Trigo, R. M.: Post-fire vegetation recovery in Portugal based on spot/vegetation data, Nat. Hazards Earth Syst. Sci., 10, 673-684, doi:10.5194/nhess-10673-2010, 2010.

Hagolle, O., Lobo, A., Maisongrande, P., Duchemin, B. and De Pereira, A.: Quality assessment and improvement of SPOT/VEGETATION level temporally composited products of remotely sensed imagery by combination of VEGETATION 1 and 2 images, Remote Sens. Environ., 94(2), 172-186, 2005.

Hartigan, J. A. and Wong, M. A.: Algorithm AS 136: A K-Means Clustering Algorithm, J. Roy. Stat. Soc. C-App., 28(1), 100-108, 1979.

Hodgkinson, K. C.: Sprouting success of shrubs after fire: height dependent relationships for different strategies, Oecologia, 115, 64-72, 1998.

Holben, B. N.: Characteristics of maximum-value composite images from temporal AVHRR data, Int. J. Rem. Sens., 7, 14171434, 1986.

Hope, A., Tague, C. and Clark, R.: Characterizing post-fire vegetation recovery of California chaparral using TM/ETM+ timeseries data, Int. J. Remote Sens., 28(6), 1339-1354, 2007.

Inbar, M., Wittenberg, L. and Tamir, M.: Soil erosion and forestry management after wildfire in a Mediterranean woodland, Mt. Carmel, Israel, Int. J. of Wild. Fire, 7, 285-294, 1998.

Jain. T. B. and Graham, R. T.: Is forest structure related to fire severity? Yes, no and maybe: Methods and insights in quantifying the answer, USDA Forest Service Proceedings RMRS-P 34, $217-$ 234, 2004.

JRC-EC: Forest Fires in Europe 2009, Report No. 10, Institute for Environment and Sustainability, European Comission, 2009.

Julien Y., Sobrino J. A., and Verhoef, W.: Changes in land surface temperatures and NDVI values over Europe between 1982 and 1999, Remote Sens. Environ., 103(1), 43-55, 2006.

Karnieli, A., Bayasgalan, M., Bayarjargal, Y., Agam, N., Khudulmur, S., and Tucker, C. J.: Comments on the use of the Vegetation Health Index over Mongolia, Int. J. Remote Sens., 27(10), 2017-2024, 2006.

Kokaly, R. L., Rockwell, B. W., Haire, S. L., and King, T. V. V.: Characterization of post-fire surface cover, soils, and burn severity at the Cerro Grande Fire, New Mexico, using hyperspectral and multispectral remote sensing, Remote Sens. Environ., 106, 305-325, 2007.

Lloret, F.: Fire, canopy cover and seedling dynamics in Mediterranean shrubland of northeastern Spain, J. Veg. Sci., 9, 417-430, 1998.

López-Soria, L. and Castell, C.: Comparative genet survival after fire in woody Mediterranean species, Oecologia, 91, 493-499, 1992.

MacQueen, J. B.: Some methods for classification and analysis of multivariate observations, Proc. 5th Berkeley Symposium on Mathematical Statistics and Probability 1, University of California Press, 281-297, 1967.

Maisongrande, P., Duchemin, B., and Dedieu, G.: VEGETA-
TION/SPOT - An Operational Mission for the Earth Monitoring: Presentation of New Standard Products, Int. J. Remote Sens., 25, 9-14, 2004.

Malkinson, D., Wittenberg, L., Beeri, O., and Barzilai, R.: Effects of repeated fires on the structure, composition, and dynamics of Mediterranean maquis: Short- and long-term perspectives, Ecosystems, 14, 478-488, 2011

Miller, J. D. and Thode, A. E.: Quantifying burn severity in a heterogeneous landscape with a relative version of the delta Normalized Burn Ratio (dNBR), Rem. Sens. Environ., 109, 66-80, 2007.

Miller, J. D., Safford, H. D., Crimmins, M., and Thode, A. E.: Quantitative evidence for increasing forest fire severity in the Sierra Nevada and Southern Cascade Mountains, California and Nevada, USA, Ecosystems, 12, 16-32, 2009.

Minchella, A., Del Frate, F., Capogna, F., Anselmi, S., and Manes, F.: Use of multitemporal SAR data for monitoring vegetation recovery of Mediterranean burned areas, Remore Sens. Environ. 113, 588-597, 2009.

Moreno, J. M. and Oechel, W. C.: The Role of Fire in Mediterranean-Type Ecosystems, Springer-Verlag, New York, USA, 1995.

Naveh. Z.: The evolutionary significance of fire in the Mediterranean region, Plant Ecol., 29(3), 199-208, 1975.

Naveh, Z.: The role of fire and its management in the conservation of Mediterranean ecosystems and landscapes, edited by: Moreno, J. M. and Oechel, W. C., The Role of Fire in Mediterranean-Type Ecosystems, Springer-Verlag, New York, USA, 163-185, 1995.

Nunes, M. C. S., Vasconcelos, M. J., Pereira, J. M. C., Dasgupta, N., Alldredge, R. J., and Rego, F. C.: Land Cover type and fire in Portugal: Do fires burn land cover selectively?, Landscape Ecol., 20, 661-673, 2005.

Pausas, G. J. and Vallejo, V. R.: The role of fire in European Mediterranean Ecosystems, Remote sensing of large wildfires in the European Mediterranean basin, edited by: Chuvieco, E., Springer-Verlag, 3-16, 1999.

Pérula, V. G., Cerrillo, R. M. N., Rebollo, P. F., and Murillo, G. V.: Postfire regeneration of Pinus Pinea L. and Pinus pinaster Aiton in Andalucia (Spain), Environ. Manage., 31(1), 86-99, 2003.

Retana, J., Espelta, J. M., Habrouk, A., Ordoñez, J. L., and de SolaMorales, F.: Regeneration patterns of three Mediterranean pines and forest changes after a large wildfire in northeastern Spain, Ecoscience 9, 89-97, 2002.

Röder, A., Hill, J., Duguy, B., Alloza, J. A., and Vallejo, R.: Using long time series of Landsat data to monitor fire events and postfire dynamics and identify driving factors. A case study in the Ayora region (eastern Spain), Remote Sens. Environ., 112, 259-273, 2008.

Shakesby, R. A., Coelho, C. O. A., Ferreira, A. D., Terry, J. P., and Walsh, R. P. D.: Wildfire impacts on soil erosion and hydrology in wet Mediterranean forest, Portugal, Int. J. of Wildland Fire 3, 95-110, 1993.

Silva, J. S., Vaz, P., Moreira, F., Catry, F., Rego, F. C.: Wildfires as a major driver of landscape Dynamics in three fire-prone areas of Portugal, Landscape and Urban Planning, 101, 349-358. 2011.

Stöckli, R. and Vidale, P. L.: European plant phenology and climate as seen in a 20-year AVHRR land-surface parameter dataset, Int. J. Remote Sens., 25, 3303-3330, 2004. 
Thornes, J.: The interaction of erosion and vegetation dynamics in land degradation: spatial outcomes, Vegetation and Erosion, Wiley, New York, 41-54, 1990.

Trigo R. M., Pereira, J. M. C., Pereira, M. G., Mota, B., Calado, M. T., DaCamara C. C., and Santo, F. E.: Atmospheric conditions associated with the exceptional fire season of 2003 in Portugal, Int. J. Climatol., 26(13), 1741-1757, 2006.

Turner, M., O’neill, R. V., Gardner, R. H., and Milne, B. T.: Effects of changing spatial scale on the analysis of landscape pattern, Landscape Ecology, 3(3/4), 153-162, 1989.
Vicente-Serrano, S. M. and Heredia-Laclaustra, A.: NAO influence on NDVI trends in the Iberian peninsula (1982-2000), Int. J. Remote Sens., 25(14), 2871-2879, 2004.

Viedma, O., Moreno, J. M., and Rieiro, I.: Interactions between land use/land cover change, forest fires and landscape structure in Sierra de Gredos (central Spain), Environmental Conservation, 33, 212-222, 2006.

Wittenberg, L., Malkinson, D., Beer, O., Halutzy, A., and Tesler, N.: Spatial and temporal patterns of vegetation recovery following sequences of forest fires in a Mediterranean landscape, Mt. Carmel Israel, Catena, Elsevier, 71(1), 76-83, 2007. 